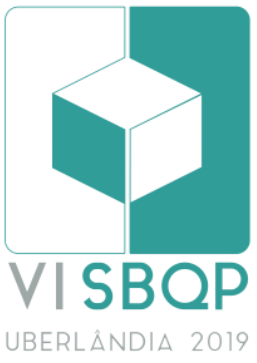

\title{
FERRAMENTA ESTATÍSTICA (ANOVA) NA ANÁLISE DA RESISTÊNCIA À COMPRESSÃO
}

\author{
REIS, Marielza Corrêa dos \\ Universidade Federal de São Carlos (PPGECiv - UFSCar), marielzabjp@hotmail.com \\ DOS REIS, Mariele Corrêa \\ Universidade Federal de São Carlos (PPGECiv - UFSCar), mariele_bjp@hotmail.com \\ SERRA, Sheyla Mara Baptista \\ Universidade Federal de São Carlos (PPGECiv - UFSCar), sheylabs@ufscar.br \\ ZAMPIERON, João Vicente \\ Universidade do Estado de Minas Gerais (UEMG - Passos), joao.zampieron@vemg.br
}

\begin{abstract}
RESUMO
Os sistemas construtivos demandam quantidades significativas de recursos naturais, entretanto, estes já começam a apresentar problemas quanto à sua escassez. A incorporação de recursos renováveis, tais como os resíduos de carvão vegetal (RCV), em compósitos cimentícios tende a minimizar tal problema. O presente estudo teve por objetivo analisar a variabilidade da resistência à compressão de argamassas com substituição parcial da areia fina por RCV e analisar estatisticamente tais resultados pela análise de variância ANOVA. De acordo com os resultados de resistência à compressão e da ANOVA, as composições com $20 \%$ RCV apresentaram melhor desempenho, em torno de $28 \mathrm{MPa}$. Tal fato comprova que a gestão integrada de sistemas nas pesquisas científicas, instiga novas tecnologias que corroboram as exigências do mercado e do meio ambiente, atentando-se para à constância na qualidade e confiabilidade dos novos produtos e da minimização de impactos ambientes.
\end{abstract}

Palavras-chave: Controle estatístico, Indicador de qualidade, Recursos renováveis, Resíduos de carvão vegetal.

\begin{abstract}
Construction systems demand significant amounts of natural resources, however, these are already beginning to present problems as to their scarcity. The incorporation of renewable resources, such as charcoal waste (RCV), in cementitious composites tends to minimize this problem. The present study had the objective of analyzing the variability of the compressive strength of mortars with partial replacement of the fine sand by RCV and to analyze these results statistically by analysis of variance ANOVA. According to the results of compressive strength and ANOVA, compositions with 20\% RCV presented better performance, around $28 \mathrm{MPa}$. This fact proves that the integrated management of systems in scientific research instigates new technologies that corroborate the demands of the market and the environment, paying attention to the constancy in the quality and reliability of the new products and the minimization of environmental impacts.
\end{abstract}

Keywords: Statistical control, Quality indicator, Renewable resources, Charcoal waste.

\section{INTRODUÇÃO}

Os sistemas construtivos demandam quantidades significativas de recursos naturais, entretanto, estes já começam a apresentar problemas quanto à sua escassez. Diante de tais demandas, locais e/ou globais, reflete-se a necessidade de novas tecnologias que atendam ao setor da construção civil

REIS, M. C.; DOS REIS, M. C.; SERRA, S. M. B.; ZAMPIERON, J. V. Ferramenta estatística (ANOVA) na análise da resistência à compressão. In: SIMPÓSIO BRASILEIRO DE QUALIDADE DO PROJETO NO AMBIENTE CONSTRUÍDO, 6., 2019, Uberlândia. Anais... Uberlândia: PPGAU/FAUeD/UFU, 2019. p. 466-470. DOI https://doi.org/10.14393/sbqp19043. 
e atuem na minimização de impactos ambientais decorrente do uso de materiais não renováveis (MOTA et al., 2017).

A incorporação de recursos renováveis, tais como os resíduos de carvão vegetal (RCV), em compósitos cimentícios abrange tais questões, além da utilização de materiais gerados em larga escala e a inserção destes em substituição a um recurso que não pode ser regenerado, como a areia fina.

Para que sejam implementados novos materiais, ainda que sustentáveis, é imprescindível a geração de dados técnicos e científicos como indicadores de qualidade e confiabilidade destes. Nesse aspecto, uma das propriedades essenciais a ser analisada em componentes cimentícios, no tocante às suas peculiaridades de aplicação, é a resistencia à compressão (TEIXEIRA; ANDRADE; BONIFÁCIO, 2015).

Fazendo vistas a esse pressuposto, o presente estudo tem por objetivo analisar a variabilidade da resistência à compressão de argamassas com substituição parcial da areia fina RCV em teores de 0\%, 10\%, $20 \%$ e 30\%, pela ferramenta estatística ANOVA (análise de variância).

\section{MATERIAIS E MÉTODOS}

\subsection{Produção das argamassas}

Para a produção das argamassas adotou-se o traço obtido em estudos realizados por Bortoletto et al. (2017). A areia fina foi substituída parcialmente pelo RCV nos teores de 0\%, 10\%, 20\% e 30\% (em volume) e a relação água/cimento foi mantida constante para todas as misturas.

\subsection{Resistência à compressão}

O ensaio de resistência à compressão foi realizado aos 7, 28 e 60 dias de idade, conforme recomendações da norma NBR 7215 (ABNT, 1996). Para cada composição foram utilizados 5 corpos de prova cilíndricos.

\subsection{Análise estatística (ANOVA)}

O planejamento experimental pretendeu enunciar as questões sobre os resultados de resistência à compressão das argamassas contendo RCV nas idades de 7, 28 e 60 dias. Para avaliar as afirmações sobre os resultados, empregou-se a técnica ANOVA, por meio do aplicativo computacional Genes, a fim de verificar se existe diferença significativa entre as médias e se os fatores exercem influência em alguma variável dependente.

Utilizou-se o teste $\mathrm{F}$ para testar as hipóteses e nos casos que constataram os pressupostos assumidos, empregou-se o Teste de Tukey, para avaliar a magnitude destas diferenças.

\section{RESULTADOS E DISCUSSÃO}

\subsection{Resistência à compressão}

Os resultados obtidos no ensaio de resistência à compressão para a argamassa com $0 \%, 10 \%, 20 \%$ e $30 \%$ de RCV em substituição à areia fina estão apresentados na Figura 1. 
Pode-se observar que, com intervalo de cura maior houve um destaque no avanço das reações de hidratação dos componentes do cimento. O aumento da resistência à compressão não obteve uma evolução tão significativa pelo fato dos RCV não se apresentarem como material pozolânico, demonstrando uma reação de hidratação mais rápida aos 7 dias e mais lenta ao passar do tempo, contando principalmente com a hidratação dos silicatos de cálcio hidratados, que se hidratam e dão resistência à matriz cimentícia.

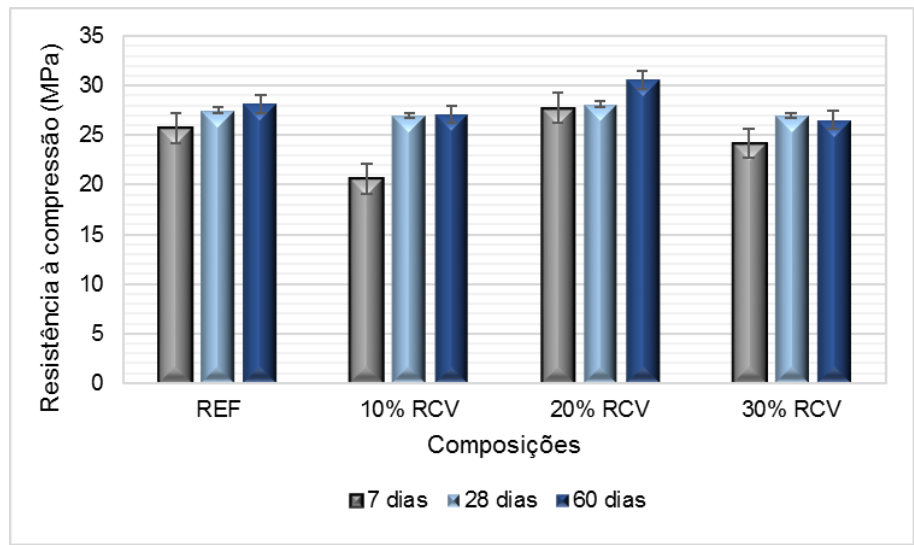

Figura 1 - Resistência à compressão das argamassas

Fonte: Autores (2019)

Considerando que todas as composições apresentaram resistências acima de $20 \mathrm{MPa}$, tal produto pode ser incorporado em componente cimentícios que não exijam resistências elevadas.

\subsection{Análise de Variância}

A variável analisada foi a resistência à compressão, as subparcelas referem-se aos traços de argamassa, as parcelas ao tempo de cura e as repetições ao número de exemplares confeccionados para cada traço. Os resultados da ANOVA, estão apresentados na Tabela 1.

Tabela 1 - ANOVA da resistência à compressão

\begin{tabular}{|c|c|c|c|c|}
\hline FV & GL & SQ & QM & F \\
\hline Parcela & 2 & 139,61 & 69,81 & 11,34 \\
\hline Erro a & 12 & 73,86 & 6,15 & - \\
\hline Subparcela & 3 & 128,49 & 42,83 & 8,47 \\
\hline Interação & 6 & 60,59 & 10,10 & 1,99 \\
\hline Erro b & 36 & 182,04 & 5,05 & - \\
\hline \multicolumn{5}{|c|}{ Fonte: Autores (2019) }
\end{tabular}

Neste estudo o enfoque é os valores de Fisher (F), os quais permite testar as hipóteses. O resultado do teste de hipótese encontra-se na Tabela 2.

Tabela 2 - Teste de hipóteses

\begin{tabular}{|c|c|c|c|c|c|}
\hline FV & TESTE & GL NUM & DL DEN & F & PROBABILIDADE (\%) \\
\hline Parcela & QMP/QMEa & 2 & 12 & 11,34 & 0,001716 \\
\hline Subparcela & QMS/QMEb & 3 & 36 & 8,47 & 0,021498 \\
\hline
\end{tabular}




\begin{tabular}{|c|c|c|c|c|c|}
\hline Interação & QMPXS/QMEb & 6 & 36 & 1,99 & $9,176706 \mathrm{~ns}$ \\
\hline
\end{tabular}

De acordo com os valores de $F$, as parcelas e as subparcelas foram significativas a $1 \%$, ou seja, a probabilidade ao nível de $5 \%$ foi significativa. Há $99 \%$ de certeza de que pelo menos um dos valores difere dos demais. A probabilidade da interação foi de 9,18\%, ou seja, não há diferença significativa estatisticamente.

Constatou-se que a inserção de RCV teve efeito significativo na resistência à compressão, assim como o tempo de cura, contudo, analisando-se a influência combinada de ambos, não houve efeito significativo no aumento da resistência. A realização da comparação de médias deu-se pelo Teste de Tukey.

Na comparação de médias das parcelas (Tabela 3), temos que os exemplares com cura aos 28 e 60 dias são estatisticamente iguais, enquanto que aos 7 dias, difere dos demais.

Tabela 3 - Comparação de médias das parcelas

\begin{tabular}{|c|c|c|}
\hline \multirow{2}{*}{ Tratamento } & \multicolumn{2}{|c|}{ TUKEY } \\
\cline { 2 - 3 } & Média & Grupo \\
\hline 60 dias & 28,11 & $\mathrm{a}$ \\
\hline 28 dias & 27,42 & $\mathrm{a}$ \\
\hline 7 dias & 24,59 & $\mathrm{~b}$ \\
\hline \multicolumn{2}{|c|}{ Fonte: Autores (2019) } \\
\hline
\end{tabular}

Na comparação de médias para as subparcelas (Tabela 4), observa-se a seguinte situação: as subparcelas de $20 \%$ RCV e 0\% RCV, 0\% RCV e 30\% RCV, e $30 \%$ RCV com 10\% RCV são similares estatisticamente, entretanto, as combinações de $20 \%$ RCV difere das argamassas com $10 \%$ RCV e 30\% RCV, e as de $0 \%$ RCV difere das de $10 \%$ RCV.

\section{Tabela 4 - Comparação de médias das subparcelas}

\begin{tabular}{|c|c|c|}
\hline \multirow{2}{*}{ Tratamento } & \multicolumn{2}{|c|}{ TUKEY } \\
\cline { 2 - 3 } & Média & Grupo \\
\hline $20 \%$ RCV & 28,84 & $\mathrm{a}$ \\
\hline $0 \%$ RCV & 27,14 & $\mathrm{ab}$ \\
\hline $30 \%$ RCV & 25,92 & $\mathrm{bc}$ \\
\hline $10 \%$ RCV & 24,92 & $\mathrm{C}$ \\
\hline \multicolumn{3}{|c|}{ Fonte: Autores (2019) } \\
\hline
\end{tabular}

\section{CONCLUSÕES}

As análises demonstraram que a incorporação de RCV em substituição a um recurso não renovável como a areia fina, é viável do ponto de vista técnico e econômico.

A gestão integrada dos sistemas nas pesquisas científicas, por meio de ferramentas estatísticas, instiga novas tecnologias que corroboram as exigências do mercado e do meio ambiente, atentando-se para à constância 
na qualidade e confiabilidade dos novos produtos e da minimização de impactos ambientes.

\section{AGRADECIMENTOS}

Ao CNPq e à CAPES, pelo apoio recebido.

\section{REFERÊNCIAS}

ASSOCIAÇÃO BRASILEIRA DE NORMAS TÉCNICAS (ABNT). NBR 7215 - Cimento Portland - Determinação da resistência à compressão. Rio de Janeiro, 1996. BORTOLETTO, M; GUIMARÃES, P.V.C.; SILVA, R.G.; AKASAKI, J.L. Avaliação do resíduo cinza da madeira de eucalipto como substituição parcial da areia em argamassas de cimento. Revista Científica ANAP Brasil, v. 10, n. 18, p. 80-93, 2017.

MOTA, L. C. S.; FERREIRA, R. H. C.; FIGUEIRA, S. L.; MONTEL, A. L. B.; D'OLIVEIRA, M. C. P. E. Avaliação dos efeitos da adição de carvão ativado residual ao concreto. In.: ANAIS DO 59 CONGRESSO BRASILEIRO DO CONCRETO 59CBC2017, Bento Gonçalves-RS, 2017.

RAMOS, F. V. Argamassas utilizando agregado leve à base de resíduo de carvão vegetal (RCV). 2015. Dissertação (Mestrado em Tecnologia de Materiais e Processos Industriais) - Universidade Freevale, FREEVALE, Brasil, 2015.

TEIXEIRA, R. F.; ANDRADE, P. C. R.; BONIFÁCIO, E. D. Análise estatística da resistência a compressão do concreto. Revista da Universidade Vale do Rio Verde, Três Corações, v. 13, n. 1, p. 635-643, 2015. 